\title{
Biological monitoring of exposure to benzene: a comparison between $S$-phenylmercapturic acid, trans,trans-muconic acid, and phenol
}

\author{
P J Boogaard, N J van Sittert
}

\begin{abstract}
Objectives-Comparison of the suitability of two minor urinary metabolites of benzene, trans,trans-muconic acid $(t t-M A)$ and $S$-phenylmercapturic acid (S-PMA), as biomarkers for low levels of benzene exposure.

Methods-The sensitivity of analytical methods of measuring $t$-MA and S-PMA were improved and applied to 434 urine samples collected from 188 workers in 12 studies in different petrochemical industries and from 52 control workers with no occupational exposure to benzene. In nine studies airborne benzene concentrations were assessed by personal air monitoring.
\end{abstract}

Results-Strong correlations were found between $t t-M A$ and $S$-PMA concentrations in samples from the end of the shift and between either of these variables and airborne benzene concentrations. It was calculated that exposure to 1 ppm (8 hour time weighted average (TWA)) benzene leads to an average concentration of 1.7 mg $t t-M A$ and $47 \mu \mathrm{g} S-P M A g$ creatinine in samples from the end of the shift. It was estimated that, on average, $3.9 \%$ (range $1.9 \%-7 \cdot 3 \%$ ) of an inhaled dose of benzene was excreted as $t t-M A$ with an apparent elimination half life of 5.0 (SD 2.3) hours and $0.11 \%$ (range $0.05 \%-0.26 \%)$ as $S$-PMA with a half life of 9.1 (SD 3.7) hours. The mean urinary $S$-PMA in 14 moderate smokers and 38 non-smokers was 3.61 and $1.99 \mu \mathrm{g} / \mathrm{g}$ creatinine, respectively and the mean urinary $t t-M A$ was 0.058 and $0.037 \mathrm{mg} / \mathrm{g}$ creatinine, respectively. S-PMA proved to be more specific and more sensitive ( $P=0 \cdot 030$, Fisher's exact test) than $t$ MA. $S$-PMA, but not $t t-M A$, was always detectable in the urine of smokers who were not occupationally exposed. S-PMA was also detectable in 20 of the 38 nonsmokers from the control group whereas $t t-M A$ was detectable in only nine of these samples. The inferior specificity of $t t-M A$ is due to relatively high background values (up to $0.71 \mathrm{mg} / \mathrm{g}$ creatinine in this study) that may be found in non-occupationally exposed people.

Conclusions-Although both $t$-MA and $S$-PMA are sensitive biomarkers, only $S$-PMA allows reliable determination of benzene exposures down to $0.3 \mathrm{ppm}(8 \mathrm{~h}$ TWA) due to its superior specificity. Because it has a longer elimination half life S-PMA is also a more reliable biomarker than $t t-M A$ for benzene exposures during 12 hour shifts. For biological monitoring of exposure to benzene concentrations higher than 1 ppm (8 h TWA) $t t-M A$ is also suitable and may even be preferred due to its greater ease of measurement.

(Occup Environ Med 1995;52:611-620)

Keywords: benzene; biomarkers; $S$-phenylmercapturic acid; trans, trans-muconic acid

The main metabolites that can be found in urine after exposure to benzene are phenol and its conjugates. ${ }^{1}$ As a consequence, total urinary phenol has been used as a biomarker for occupational exposure to benzene for a long time. Its use, however, is limited to benzene concentrations over $5 \mathrm{ppm}\left(16 \mathrm{mg} / \mathrm{m}^{3}\right)$ as an 8 hour time weighted average (TWA) because a substantial background of phenol may be found in non-exposed people due to dietary habits. In many countries, however, the occupational limit concentration for airborne benzene will be, or has already been, lowered to $1 \mathrm{ppm}$ ( $8 \mathrm{~h}$ TWA). In some countries even lower values have been adopted (Sweden $0.5 \mathrm{ppm}$ ) or proposed (United States $0.3 \mathrm{ppm}$ ). As a consequence new biomarkers are needed. Although measurement of benzene itself either in blood or exhaled air is both highly specific and sensitive, ${ }^{23}$ urinary measurements are preferred in occupational medicine as collection of urine is not only non-invasive but also easily performed even at distant working locations. Over the past few years two minor urinary metabolites of benzene have been introduced as new biomarkers for determination of benzene exposure: trans,trans-muconic acid (tt-MA, 2,4-hexadienedioic acid) ${ }^{4-11}$ and $S$-phenylmercapturic acid (S-PMA, $N$-acetyl-S-phenyl-L-cysteine). ${ }^{12-14}$ We applied these two markers in a series of studies in industrial workers with potential exposure to benzene to determine their comparative suitability for biological monitoring.

\section{Methods and materials}

POPULATIONS AND COLLECTIONS OF URINARY AND AIRBORNE SAMPLES

For the estimation of normal values of urinary $t t$-MA, a study was conducted in 46 employees from the technical and six employees from 


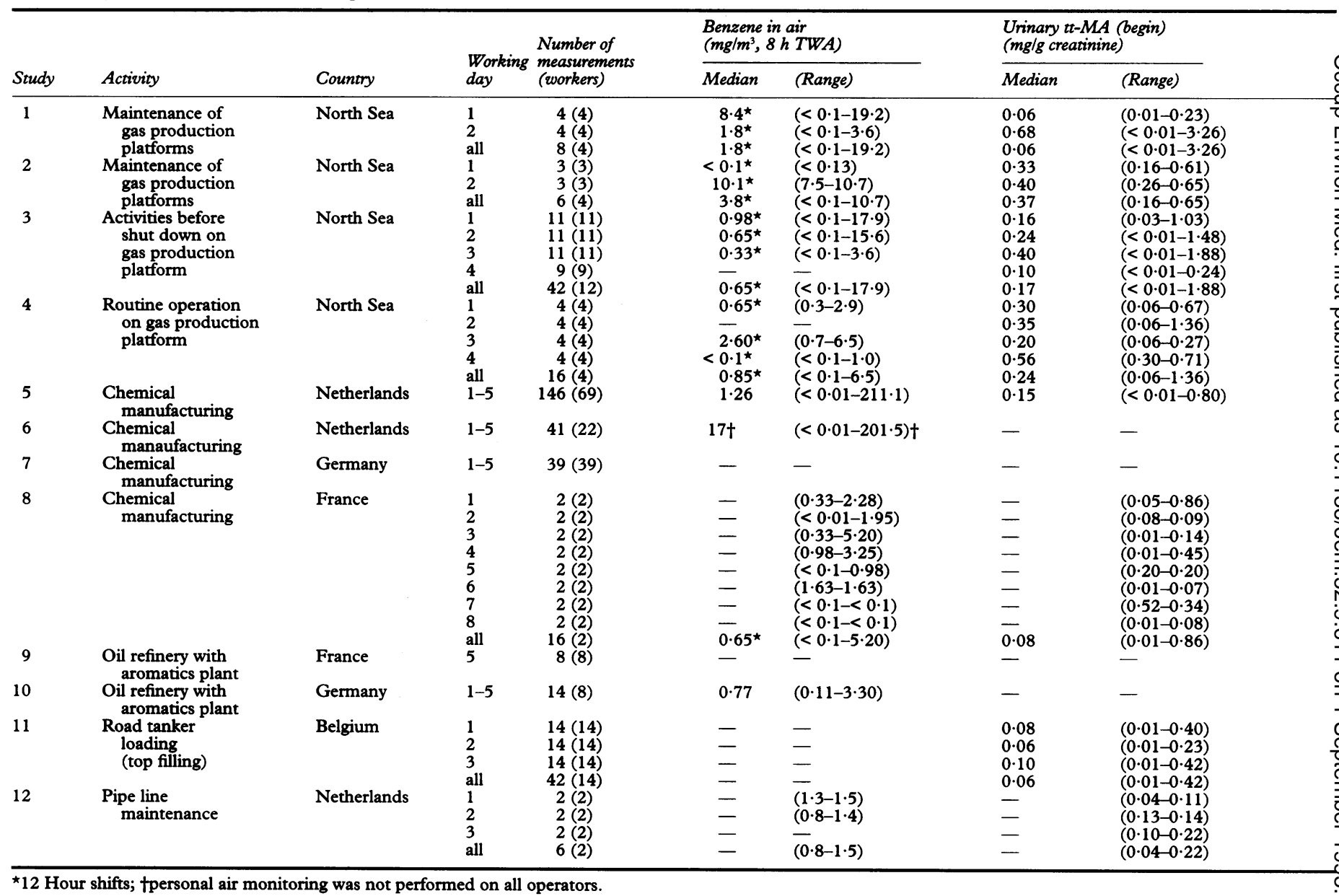

$\star 12$ Hour shifts; tpersonal air monitoring was not performed on all operators.

the medical department who were not occupationally exposed to benzene (controls). This control group comprised 14 smokers and 38 non-smokers.

For the comparison of the methods, 12 studies in eight locations (four countries) have been performed in the period from 1992 to 1994 on workers who were potentially exposed to benzene during manufacturing and maintenance operations in natural gas production installations, in refineries, and in chemical plants (table).

Four surveys were carried out in 1992 during various maintenance operations on natural gas production platforms in the North Sea.

Studies 1 and 2 were both performed on two consecutive days, each on four workers involved in small maintenance operations. Personal air monitoring was carried out on these eight workers for the whole 12 hour shift with charcoal tubes and personal sampler pumps (flow rate about $100 \mathrm{ml} / \mathrm{min}$ ). The detection limit of airborne benzene was 0.1 $\mathrm{mg} / \mathrm{m}^{3}$ (12 h TWA). The occupational hygienist involved noticed skin contact in study 1 on four occasions (three people). All the participants provided urine samples before and after the shift for determination of $S$ PMA and $t t$-MA (in total 16 samples for study 1 and 12 samples for study 2). In the urinary samples of two operators from study 1 (eight samples) and three operators from study 2 (seven samples) who had airborne exposure to benzene higher than $1.5 \mathrm{ppm}$ (12 h TWA) urinary phenol concentrations were also measured.

Study 3 was performed on 16 people engaged in activities before shut down. Only five people were involved for one day, the other 11 people were involved for two to four consecutive 12 hour shifts. Personal air sampling was carried out on these 11 people as described for study 1 . All 16 people provided urine samples before and after the shift on each working day and nine of the 11 people who worked more than one day provided an additional urine sample 12 hours after the end of the last shift. One worker did not provide a sample at the end of the shift on day 3. Both $S$-PMA and $t t-M A$ were determined in all 83 urine samples. Also phenol was measured in 18 urine samples of workers with airborne benzene concentrations higher than $2 \mathrm{mg} / \mathrm{m}^{3}$ (12 h TWA).

Study 4 was performed on four consecutive days (12 hour shifts) on four people involved in routine small maintenance operations. Personal air monitoring was carried out as described for study 1 . From all workers urine samples were collected before and after the shift for measurement of $S$-PMA and $t t-M A$ (32 samples in total). For two people with relatively high benzene exposures phenol measurements were also made. 


\begin{tabular}{|c|c|c|c|c|c|}
\hline \multicolumn{2}{|c|}{$\begin{array}{l}\text { Uninary } t t-M A(e n d) \\
\text { (mg/g creatinine) }\end{array}$} & \multicolumn{2}{|c|}{$\begin{array}{l}\text { Urinary } S-P M A \text { (begin) } \\
\text { ( } \mu g / g \text { creatinine) }\end{array}$} & \multicolumn{2}{|c|}{$\begin{array}{l}\text { Urinary } S \text {-PMA (end) } \\
\text { (ug/g creatinine) }\end{array}$} \\
\hline Median & (Range) & Median & (Range) & Median & (Range) \\
\hline $\begin{array}{l}4 \cdot 62 \\
1 \cdot 05 \\
1 \cdot 05 \\
0 \cdot 48 \\
2 \cdot 59 \\
1 \cdot 60 \\
0 \cdot 67 \\
0 \cdot 77 \\
0 \cdot 37 \\
0 \cdot 40 \\
0 \cdot 40 \\
0 \cdot 35 \\
0 \cdot 22 \\
1 \cdot 07 \\
0 \cdot 43 \\
0 \cdot 24 \\
1 \cdot 53\end{array}$ & 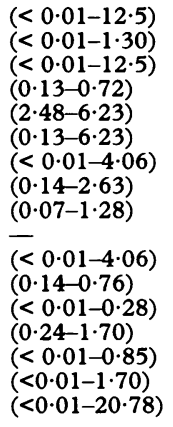 & $\begin{array}{r}<3 \\
145 \\
5 \\
12 \\
20 \\
17 \\
3 \\
17 \\
19 \\
7 \\
7 \\
3 \\
6 \\
2 \\
6 \\
4 \\
7\end{array}$ & $\begin{array}{l}(<1-5) \\
(2-496) \\
(<1-496) \\
(4-104) \\
(14-34) \\
(4-104) \\
(<1-23) \\
(4-143) \\
(5-43) \\
(2-17) \\
(1-143) \\
(2-17) \\
(5-49) \\
(2-9) \\
(5-45) \\
(2-49) \\
(2-46)\end{array}$ & $\begin{array}{r}151 \\
35 \\
35 \\
15 \\
131 \\
44 \\
18 \\
15 \\
12 \\
-12 \\
12 \\
6 \\
4 \\
11 \\
10 \\
6 \\
36\end{array}$ & $\begin{array}{l}(<1-798) \\
(3-70) \\
(<1-798) \\
(3-23) \\
(64-175) \\
(3-175) \\
(5-392) \\
(1-60) \\
(3-51) \\
(1-392) \\
(5-25) \\
(<2-10) \\
(5-66) \\
(1-15) \\
(<2-66) \\
(2-2312)\end{array}$ \\
\hline $1 \cdot 61$ & $(0 \cdot 13-39 \cdot 49)$ & - & - & 38 & $(20-1175)$ \\
\hline 1.08 & $(0 \cdot 18-18 \cdot 18)$ & - & - & 12 & $(3-277)$ \\
\hline $\begin{array}{l}\overline{-} \\
\overline{-} \\
\overline{-} \\
\overline{-} \\
\overline{0} \\
0 \cdot 13 \\
0 \cdot 18\end{array}$ & $\begin{array}{l}(0.26-0.09) \\
(0.11-1.97) \\
(0.01-4.20) \\
(0.08-2.42) \\
(0.15-0.81) \\
(0.74-0.35) \\
(0.01-0.01) \\
(0.01-0.05) \\
(0.01-4.20) \\
(0.01-0.48)\end{array}$ & $\begin{array}{l}= \\
= \\
= \\
= \\
- \\
{ }^{5}\end{array}$ & $\begin{array}{l}(2-3) \\
(1-12) \\
(2-40) \\
(1-92) \\
(1-31) \\
(4-20) \\
(21-22) \\
(1-5) \\
(1-92) \\
-\end{array}$ & $\begin{array}{l}- \\
= \\
= \\
= \\
= \\
12 \\
26\end{array}$ & $\begin{array}{l}(11-22) \\
(4-66) \\
(4-133) \\
(3-143) \\
(1-41) \\
(18-17) \\
(9-5) \\
(<2-12) \\
(1-143) \\
(3-85)\end{array}$ \\
\hline 0.55 & $(0 \cdot 11-1 \cdot 51)$ & - & - & 12 & $(2-98)$ \\
\hline $\begin{array}{l}0 \cdot 17 \\
0 \cdot 28 \\
0 \cdot 20 \\
0 \cdot 21 \\
- \\
- \\
-\end{array}$ & $\begin{array}{l}(0.01-0.53) \\
(0.08-0.61) \\
(0.05-1.05) \\
(0.01-1.05) \\
(0.50-0.57) \\
(0.56-0.57) \\
\frac{1}{(0.50-0.57)}\end{array}$ & $\begin{array}{r}1 \\
4 \\
5 \\
3 \\
- \\
- \\
-\end{array}$ & $\begin{array}{l}(<1-11) \\
(1-14) \\
(1-13) \\
(<1-14) \\
(2-4) \\
(2-14) \\
(1-21) \\
(1-21)\end{array}$ & $\begin{array}{r}6 \\
5 \\
5 \\
6 \\
- \\
- \\
-\end{array}$ & $\begin{array}{l}(1-13) \\
(1-34) \\
(2-38) \\
(1-38) \\
(3-21) \\
(3-24) \\
(3-24)\end{array}$ \\
\hline
\end{tabular}

Four studies were carried out during routine operations in chemical plants.

Study 5 took place in 1992 in The Netherlands and involved 69 people who worked in the production of ethyl benzene from benzene. Forty of them were biologically monitored only once by measurement of urinary metabolites in samples collected both at the beginning and the end of the eight hour shift (seven people) or only at the end of the shift (33 people). The other 29 people were biologically monitored on between two to 12 different days. In total 169 samples were collected and analysed for S-PMA and $t t-M A$, in 115 samples phenol was also measured. Personal air sampling was performed in 44 workers for the full shift on one or more days (90 samples in total) with passive dosimeters (3M gas diffusion batches, type 3500 ). The detection limit of airborne benzene was $0 \cdot 1$ $\mathrm{mg} / \mathrm{m}^{3}$ (8 $\mathrm{h}$ TWA).

Study 6 was carried out in the same plant in 1993 on 22 people who provided 41 urine samples collected at the end of the 8 hour shift on between one and four different days. In all samples $t t$-MA and $S$-PMA were determined, but no measurements of phenol were made. Personal air monitoring was carried out as in study 5 on eight people (13 samples in total).

Study 7 was carried out in 1993 on 39 workers in a chemical plant in Germany who handled benzene. Exposure to benzene was monitored by measurement of urinary $t t-\mathrm{MA}$ and S-PMA. From all workers a single urine sample was collected at the end of the 8 hour shift. No personal air sampling was performed.

Study 8 involved two people in a chemical plant in France who were biologically monitored for benzene exposure on eight consecutive days by measurement of $t t-M A$ and $S$-PMA in urine samples from before and after the shift. In 12 selected samples phenol was also measured. Personal air sampling was carried out in all 12 hour shifts, as in study 5 .

Two studies were carried out in 1992 in oil refineries with aromatic plants in France and Germany. Study 9 was carried out on eight people who collected a single urine sample at the end of the shift. In the samples $t t-M A$, $S$-PMA, and phenol were measured. No air measurements were carried out. Study 10 was performed on eight workers who provided urine samples at the end of the shift once, on the last day of the week (two people), or twice, on the third and fifth day of the five day working week (six people). Both $t t-\mathrm{MA}$ and $S$-PMA were measured in all samples, phenol was measured in three selected samples. Air sampling was by personal sampler pumps (flow rate between 40 and $80 \mathrm{ml} / \mathrm{min}$ ) with charcoal as the absorbent. The detection limit was $0.01 \mathrm{mg} / \mathrm{m}^{3}$ ( $8 \mathrm{~h} \mathrm{TWA}$ ).

Study 11 was performed in 1992 in Belgium on 14 drivers of road tankers who were involved in loading the tanker (top filling) with petrols containing an average of $3 \%$ $\mathrm{v} / \mathrm{v}$ of benzene. ${ }^{15}$ The drivers were biologically monitored by measurement of $t t-\mathrm{MA}$ and $S$-PMA in urine samples collected at the beginning and the end of the 8 hour shift on three consecutive days. Air monitoring of benzene was performed as in study 5 . Individual data were not available.

Study 12 was carried out in The Netherlands in 1994 on two men involved in cleaning and maintenance operations for two days on a pipeline system used to transport naphthas with a high content of aromatic compounds. The men were biologically monitored by measurement of $t t-M A$ and S-PMA in urine samples taken before and after the shift and at the beginning of the third day. Air sampling during the activities was carried out with charcoal tubes and personal sampler pumps (flow rate about $200 \mathrm{ml} / \mathrm{min}$ ).

In all studies, urine samples were collected in polythene bottles and acidified to $\mathrm{pH} 2$ with $6 \mathrm{M}$ hydrochloric acid on site. Stability studies of $t t-M A, S-P M A$, and phenol in urine had shown that under these conditions concentrations did not change if stored at room temperature or $4^{\circ} \mathrm{C}$ for at least a month..$^{913}$ The samples were transported to the Shell Biomedical Laboratory, Rotterdam, for measurement of urinary benzene metabolites and creatinine. Urinary creatinine was measured to adjust for the variations in concentration of urine samples due to differences in fluid intake between workers. Urinary creatinine was previously shown to provide a good 
correction for spot samples if 24 hour samples could not be collected ${ }^{13}$ and it concomitantly allows adjustment for the variable dilution introduced by the acidification of the samples. Personal air sampling and benzene analyses were performed by local staff.

\section{MEASUREMENT OF URINARY METABOLITES}

The measurement of phenol and creatinine have been described previously. ${ }^{13}$ The $S$-PMA was also measured as described previously, ${ }^{13}$ but as an internal standard deuterium labelled S-PMA was used instead of $S$-benzylmercapturic acid ( $S$-BMA). The $S$ [pentadeuterophenyl]mercapturic acid $\left(\mathrm{d}_{5}-S\right.$ PMA) was synthesised from ring- $d_{5}$ aniline with the Gattermann reaction according to Rumpf $^{16}$ and was recrystallised twice from ethanol with water. The use of $d_{5}-S-P M A$ as an internal standard allowed a limit of detection of $1 \mu \mathrm{g} / \mathrm{l}$. A series of urine samples were pooled, spiked with $S$-PMA at two different concentrations, acidified, and stored frozen at $-20^{\circ} \mathrm{C}$. In all runs a set of samples from this urine pool was analysed to check the reproducibility of the method. The coefficient of variation between different runs $(n=42)$ was $8.9 \%$ for the pool with $28 \mu \mathrm{g} S-\mathrm{PMA} / 1$ and $6 \cdot 1 \%$ for the pool with $104 \mu \mathrm{g} S$-PMA/l. The coefficient of variation of replicate analyses ( $n=10$ ) was $2.5 \%$ and $3.5 \%$ at spiked concentrations of $13 \cdot 1$ and $50 \cdot 1 \mu \mathrm{g} S-\mathrm{PMA} / 1$, respectively. With this procedure up to 30 urine samples could be analysed in one day.

The measurement of $t t$-MA was essentially that of Ducos et al. ${ }^{5}$ In our hands, this method gave non-reproducible recoveries. It seemed that the recovery was dependent on both the urinary $\mathrm{pH}$ and the brand of the quaternary ammonium ion exchange resin (SAX columns) used. With some brands poor recoveries were obtained with slightly acidic urines. Therefore, the urine samples were brought to pH 7-10 by addition of $35 \%$ (w/v) aqueous sodium hydroxide solution before the sample was cleaned up by solid phase extraction. An aliquot of $1.00 \mathrm{ml}$ of urine was subsequently passed through a SAX column. The column

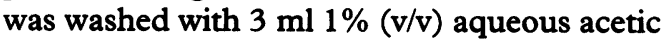
acid and the $t t-\mathrm{MA}$ eluted with $4 \mathrm{ml} 10 \%$ (v/v) aqueous acetic acid into calibrated tubes and the volume was made up to $5.0 \mathrm{ml}$ with purified water. Aliquots $(20 \mu \mathrm{l})$ of this solution were analysed by high performance liquid chromatography (HPLC) with UV $(\lambda=259$ $\mathrm{nm}$ ) detection (Hewlett Packard 1084B) at $20^{\circ} \mathrm{C}$ with a $100 \times 2 \cdot 1 \mathrm{~mm}$ stainless steel column with Spherisorb 5 ODS-2 as the immobile phase and $20 \%(\mathrm{v} / \mathrm{v})$ methanol in $1 \%$ (v/v) aqueous acetic acid as the mobile phase. The flow rate was set at $1 \mathrm{ml} / \mathrm{min}$. For calibration, a series of $t t-M A$ standards in fresh control urine samples were analysed together with the urine samples. Alkalisation of the urine samples before the solid phase extraction greatly improved the reproducibility: optimum recoveries (invariably over 95\%) were obtained if the urinary $\mathrm{pH}$ ranged from 7 to 10. A more effective clean up was a side effect of the alkalisation of the samples, which lowered the detection limit to $0.01 \mathrm{mg} / 1$. The coefficient of variation of replicate analyses $(n=10)$ was $3 \cdot 2 \%$ at a spiked concentration of $0.64 \mathrm{mg} / \mathrm{l}$ and $0.4 \%$ at a spiked concentration of $5.55 \mathrm{mg} / \mathrm{l}$. The reproducibility was tested by analysis of a set of identical samples in a series $(n=6)$ of runs. The coefficient of variation was $11 \%$ for samples spiked with $1.11 \mathrm{mg} t t-\mathrm{MA} / \mathrm{l}$ and $2.7 \%$ for samples spiked with $5.57 \mathrm{mg} t t-\mathrm{MA} / 1$. With this procedure, up to 40 urine samples could be analysed in one day.

\section{MEASUREMENT OF BENZENE IN AIR}

The benzene vapours adsorbed on the gas diffusion badges or the charcoal tubes during personal air sampling were desorbed by carbon disulphide and the solution was analysed with a gas chromatographic method with flame ionisation detection according to standard methods published by the National Institute for Occupational Safety and Health (NIOSH). ${ }^{17}$

\section{CALCULATIONS AND STATISTICS}

The cumulative excretions of $t t-M A$ and $S$ PMA were estimated from the area under the curve of urinary excretion $v$ time plots and were used to estimate the percentages of the respiratory benzene dose excreted as $t t-\mathrm{MA}$ and S-PMA in the urine. For 14 workers, mainly from studies 3,4 , and 8 personal air monitoring data as well as sufficient biological monitoring data were available both to estimate the respiratory benzene doses and to calculate the areas under the curve. For the calculation of these areas the linear trapezoidal rule was used in the absorption phases and the logarithmic trapezoidal rule in the elimination phases. The following formula was used for the logarithmic trapezoidal rule:

$$
\begin{aligned}
& \text { area under the curve } e_{(1-2)}=0.0625 \times \\
& \left(\left(c_{1}-c_{2}\right) \times\left(t_{2}-t_{1}\right)\right) /\left(\ln \left(c_{1}\right)-\ln \left(c_{2}\right)\right),
\end{aligned}
$$

where 0.0625 is the average urinary volume $(\mathrm{l} / \mathrm{h}), \mathrm{c}_{1}$ denotes the concentration of metabolite (either $t t-M A$ or $S$-PMA) in the urine sample collected at time $t_{1}$ (end of the shift) and $c_{2}$ the concentration of metabolite at time $t_{2}$ (next morning) during the elimination phase $\left(c_{1}>c_{2}\right)$. The absorbed benzene dose was estimated with the formula:

$$
\text { dose }=0.47 \times \mathrm{C} \times \mathrm{V} \text {, }
$$

where 0.47 is the fraction of benzene that is retained upon inhalation, ${ }^{18} \mathrm{C}$ denotes the airborne concentration ( $\mathrm{mg}$ benzene $/ \mathrm{m}^{3}$ ) and V the average respiratory volume $\left(1 \cdot 25 \mathrm{~m}^{3} / \mathrm{h}\right)$.

Both for $t t-M A$ and S-PMA apparent urinary elimination rate constants were calculated from workers who had provided urine samples at the beginning and end of a shift on at least two consecutive days. For the calculation of the apparent elimination rate constants $\left(k_{e}\right)$ it was assumed that the absorption was completed and that first order elimination kinetics were obeyed during the collection period. The following formula was used:

$$
\ln \left(c_{2} / c_{1}\right)=-k_{e} \times\left(t_{2}-t_{1}\right),
$$

where $c_{1}$ denotes the concentration of metabolite (either $t t-\mathrm{MA}$ or $S$-PMA) in the urine 
sample collected at the end of the shift at time $t_{1}$ and $c_{2}$ the concentration of metabolite at the beginning of the next day shift at time $t_{2}$. Occasionally, when the absorption phase was not yet completed at the end of the shift $\left(t_{1}\right)$, $c_{2}$ was higher than $c_{1}$. In these cases $k_{e}$ was calculated from the decline in metabolite during the same shift but only if there was no detectable exposure to benzene. In these cases $c_{1}$ denotes the concentration of metabolite (either $t t$-MA or S-PMA) in the urine sample collected at the beginning of the shift (at time $t_{1}$ ) and $c_{2}$ the concentration of metabolite at the end of the same shift (at time $t_{2}$ ). For most workers values of $k_{e}$ could be calculated more than once; in these cases the separate values were averaged. From the averaged values the corresponding half life $\left(t_{1 / 2}\right)$ was calculated for each worker with the following formula:

$$
t_{1 / 2}=-\ln (2) / k_{e} \text {. }
$$

For all statistical calculations the mainframe version of the SAS software package (version 6.07 or 6.08 ) was used. For S-PMA and $t t^{-}$ MA results below the calculated value for the limit of detection of the respective methods half of this value was substituted.
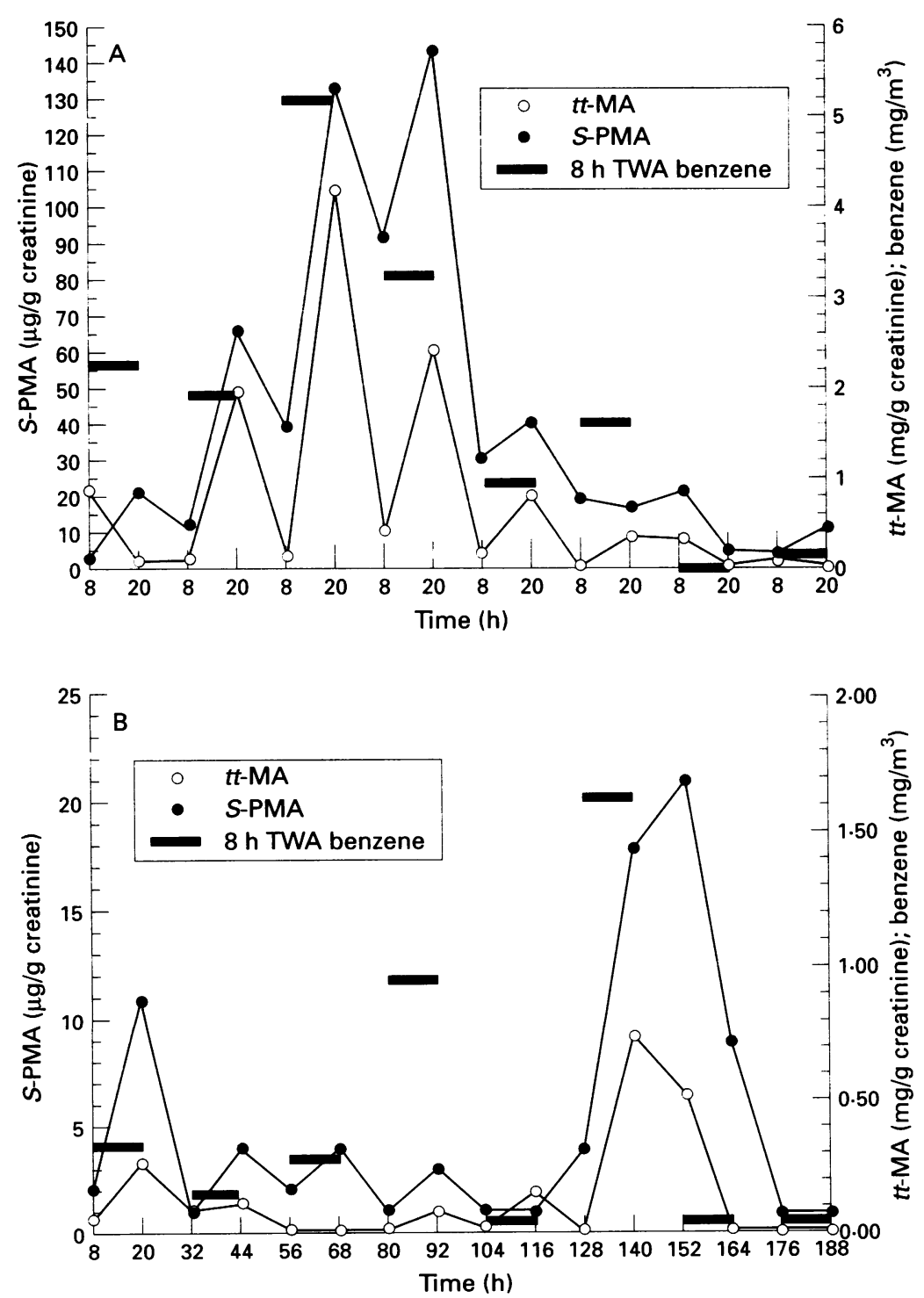

Figure 1 Urinary excretion of $t t-M A$ and S-PMA in two workers ( $A$ and $B$ ) after exposure to benzene on eight consecutive days.

\section{Results}

URINARY $t$-MA AND $s$-PMA IN WORKERS WITH NO OCCUPATIONAL EXPOSURE

The 38 non-smokers in the control group had a mean (SEM) urinary $t$-MA concentration of $0.037(0.016)$ and the 14 smokers 0.058 $(0.013) \mathrm{mg} / \mathrm{g}$ creatinine. The mean (SEM) $S$ PMA concentration in the 38 non-smokers was $1.99(0.29)$ and in the 14 smokers 3.61 $(0.57) \mu \mathrm{g} / \mathrm{g}$ creatinine. $S$-PMA was present at detectable concentrations in the urine of all smokers and in 20 of the 38 non-smokers. This showed the superior sensitivity $(P=$ 0.030 , Fisher's exact test) of S-PMA over $t t-M A$, for which urinary concentrations were below the detection limit in three smokers and 29 non-smokers. Although the detectability (yes, no) of both biomarkers was strongly correlated with smoking (yes, no) $(P<0.0001$, Fisher's exact test), multivariate regression analysis disclosed no correlation with the number of cigarettes smoked and either $S$ PMA or $t t-M A$.

URINARY $t t$-MA AND $S$-PMA IN OCCUPATIONALLY EXPOSED POPULATIONS

The table gives an overview of the results obtained in the 12 studies in industrial workers with potential exposure to benzene. The high airborne benzene concentrations measured in studies 1,2 , and 3 (up to $19 \cdot 2 \mathrm{mg} / \mathrm{m}^{3}$ ) did not reflect normal operations but peak exposures measured in selected operators with relatively high potential exposure to aromatic compounds during special maintenance operations on gas production platforms. Both $t t$-MA and $S$-PMA excretion increased over the shift and reflected the airborne benzene exposure. During routine operations (study 4) benzene exposure was usually far below $1 \mathrm{ppm}\left(3.25 \mathrm{mg} / \mathrm{m}^{3}\right)$ but, nevertheless, increases in both $t t$-MA and $S$-PMA were found. In the urine samples provided by operators with relatively high benzene exposures $(>0.5 \mathrm{ppm})$ phenol was also measured. It seemed that phenol correlated well with both $t t$-MA and S-PMA in operators with low background values of phenol $(<5 \mathrm{mg} / \mathrm{g}$ creatinine). The very high exposures in studies 5 and 6 (up to $211 \mathrm{mg} / \mathrm{m}^{3}$ ) also represented selected operators who had incidental peak exposures due to accidental spillage during maintenance operations. In $68 \%$ of the samples collected in study 5 phenol measurements were also carried out. The correlation of phenol with $t t-M A$ as well as with $S$-PMA was rather poor: there were several increased values of phenol ( $\geqslant 50 \mathrm{mg} / \mathrm{g}$ creatinine) without concurrent exposure or substantially increased $t t$-MA or $S$-PMA, and occasionally phenol was not increased $(\leqslant 5 \mathrm{mg} / \mathrm{g}$ creatinine) although both $t t-M A$ and $S$-PMA were clearly increased $(t t-\mathrm{MA} \geqslant 1 \mathrm{mg} / \mathrm{g}$ creatinine or $S$-PMA $\geqslant 45 \mu \mathrm{g} / \mathrm{g}$ creatinine). During operations in oil refineries with aromatic plants (studies 9 and 10) exposures were generally well below $1 \mathrm{ppm}$. In all cases distinct increases in both $t t-M A$ and $S$-PMA were found in the samples collected at the end of the shift compared with those collected at the beginning. 
URINARY EXCRETION OF $t t$-MA AND $s$-PMA OVER TIME

Figure 1 depicts the urinary excretion $v$ time plots from the two workers from study 8 , who were biologically monitored for eight consecutive days. The results of the personal air measurements for benzene are shown in the graphs as bars. The first worker (A) was exposed to relatively high concentrations of benzene up to $5.2 \mathrm{mg} / \mathrm{m}^{3}(1.6 \mathrm{ppm})$ on the third working day. The second worker was exposed to much lower concentrations of benzene: the highest exposure was recorded on the sixth working day and was $1.63 \mathrm{mg} / \mathrm{m}^{3}$ $(0.5 \mathrm{ppm})$. It is clear, especially from the excretion profile of the more highly exposed worker, that the excretion of $t t-\mathrm{MA}$ and $S$ PMA follow roughly the same pattern and that the excretion of both metabolites reflect the exposure to benzene. It is also clear that, due to the shorter apparent half life of $t t-\mathrm{MA}$ than $S$-PMA, $t t$-MA returns to baseline values at the beginning of the next shift after exposures up to $1 \mathrm{ppm}$ whereas $S$-PMA tends to accumulate at exposures over about $0.5 \mathrm{ppm}$.

\section{TOXICOKINETICS OF $t t$-MA AND $s$-PMA}

Twenty nine workers provided urine samples on at least two consecutive days. For 27 workers values for the apparent urinary excretion constants could be calculated from 52 and 38 data points for $t t-M A$ and $S$-PMA, respectively. The median $\mathrm{k}_{\mathrm{e}}$ for $t t-\mathrm{MA}$ was $0.136 \mathrm{l} / \mathrm{h}$ and for $S$-PMA $0.077 \mathrm{l} / \mathrm{h}$. These values correspond to median apparent elimination half lives of $5 \cdot 1$ (mean (SD) $5 \cdot 0(2 \cdot 3)$ ) hours and $9 \cdot 0(9 \cdot 1(3 \cdot 7))$ hours, respectively. For 14 workers sufficient personal air monitoring and biological monitoring data were collected to allow an estimation of the urinary excretion of $t t$-MA and $S$-PMA as a percentage of the dose of inhaled benzene. The average percentage of the dose that was excreted as $t t-\mathrm{MA}$ was $3.9 \%$ (range $1.9 \%-7 \cdot 3 \%$ ) and as $S$-PMA was $0.11 \%$ (range $0.05 \%-0 \cdot 26 \%$ ).

\section{RELATION BETWEEN DIFFERENT URINARY} METABOLITES OF BENZENE

In fig 2 the $t t-M A$ concentrations were plotted against the $S$-PMA concentration in the same urine sample, both after logarithmic transformation, for all 188 workers from studies 1-12. If for a worker more than one set of values was measured, the set of values corresponding to the highest airborne benzene concentration was chosen, or if no air measurements were performed, the set with the highest values. A highly significant correlation between $t t-\mathrm{MA}$ and $S$-PMA was found $(r=0.795, \mathrm{P}<$ $0.0001)$. Nevertheless, some deviations were found. In some cases where no exposure to benzene had occurred, relatively high concentrations of $t t$-MA (up to $0.71 \mathrm{mg} / \mathrm{g}$ creatinine) were measured in the urine (without high concentrations of $S$-PMA: $\leqslant 1 \mu \mathrm{g} / \mathrm{g}$ creatinine).

An exceptional finding was made in study 12. The two workers involved in this study carried out the same job in close vicinity of each other. Figure 3 shows the results of the personal air monitoring and the values of $S$-PMA and $t t-M A$. It seems that on the first day the airborne concentrations of benzene are more or less identical for both men. One of the workers (closed symbols) excreted both $S$-PMA and $t t$-MA in concentrations that match the concentration of benzene in air. In the urine of the other man $t t-\mathrm{MA}$ was found as expected, but surprisingly no increases in $S$-PMA were found. From the medical records it seemed that this worker was treated for epilepsy with high doses of carbamazepine, a known inducer of hepatic mixed function oxidases.
Figure 2 Relation between urinary concentrations of $t t-M A$ and $S-P M A$ in 188 workers exposed to benzene.
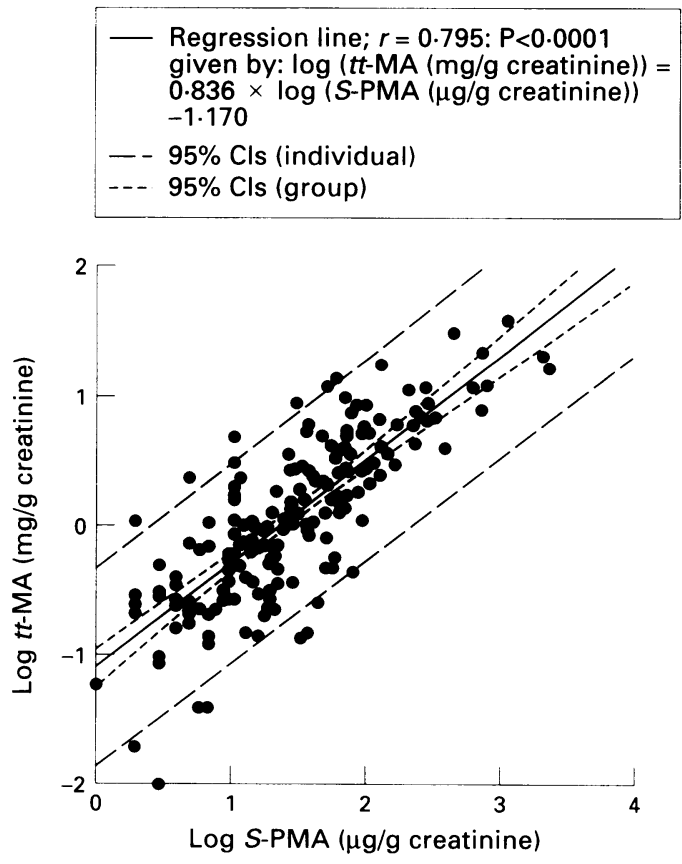

Figure 3 Urinary excretion of $t-M A$ and $S-P M A$ in two workers $(A$ and $B)$ after exposure to benzene on two consecutive days. 
Figure 4 Relation between respiratory $8 h$ $T W A$ exposure to benzene and concentrations of $t \mathrm{t}-$ $M A$ and $S-P M A$ in urinary samples collected at the end of an $8 \mathrm{~h}$ shift from 58 workers from studies 5 , 6,10 , and 12 .
Figure 5 Relation between respiratory $12 \mathrm{~h}$ $T W A$ exposure to benzene and concentrations of $t$ $M A$ and $S-P M A$ in urinary samples collected at the end of a $12 \mathrm{~h}$ shift from 28 workers from studies $1-4$ and 8.
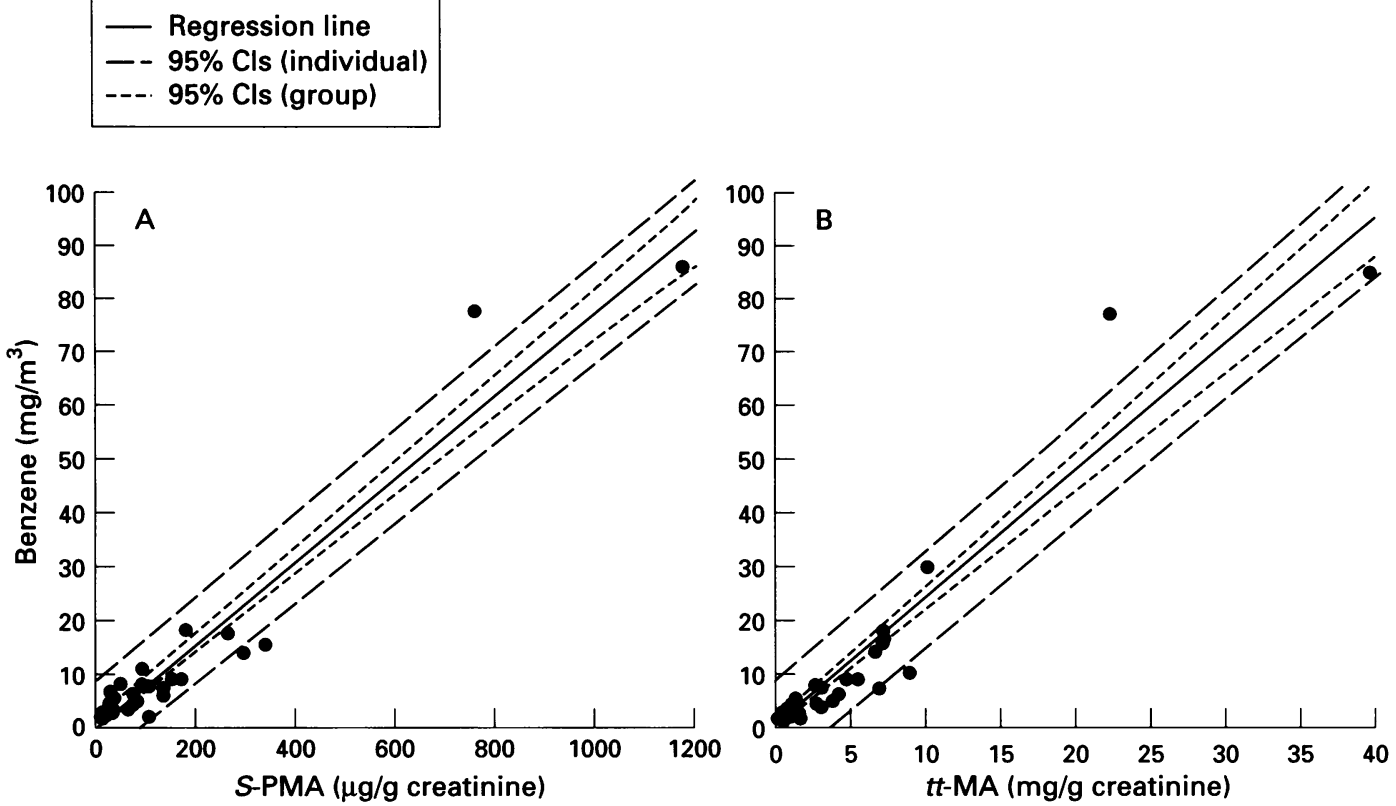

CORRELATION OF AIRBORNE BENZENE AND URINARY EXCRETION OF METABOLITES

The relation between airborne benzene exposures ( $8 \mathrm{~h}$ TWA) and urinary $S$-PMA and $t t-M A$ concentrations was examined in samples collected at the end of the shift from 58 workers in studies $5,6,10$, and 12 . The actual working hours in these studies were close to eight hours. Data from workers who had worn respiratory protection during the monitoring period were excluded from the statistics. In cases where more than one data point had been generated for a worker, the data point with the highest airborne benzene concentration was used for the linear regression analysis. Highly significant correlations ( $\mathrm{P}<0.0001$ ) were found for both S-PMA and $t t-M A$ (fig 4). The equations for the regression lines were:
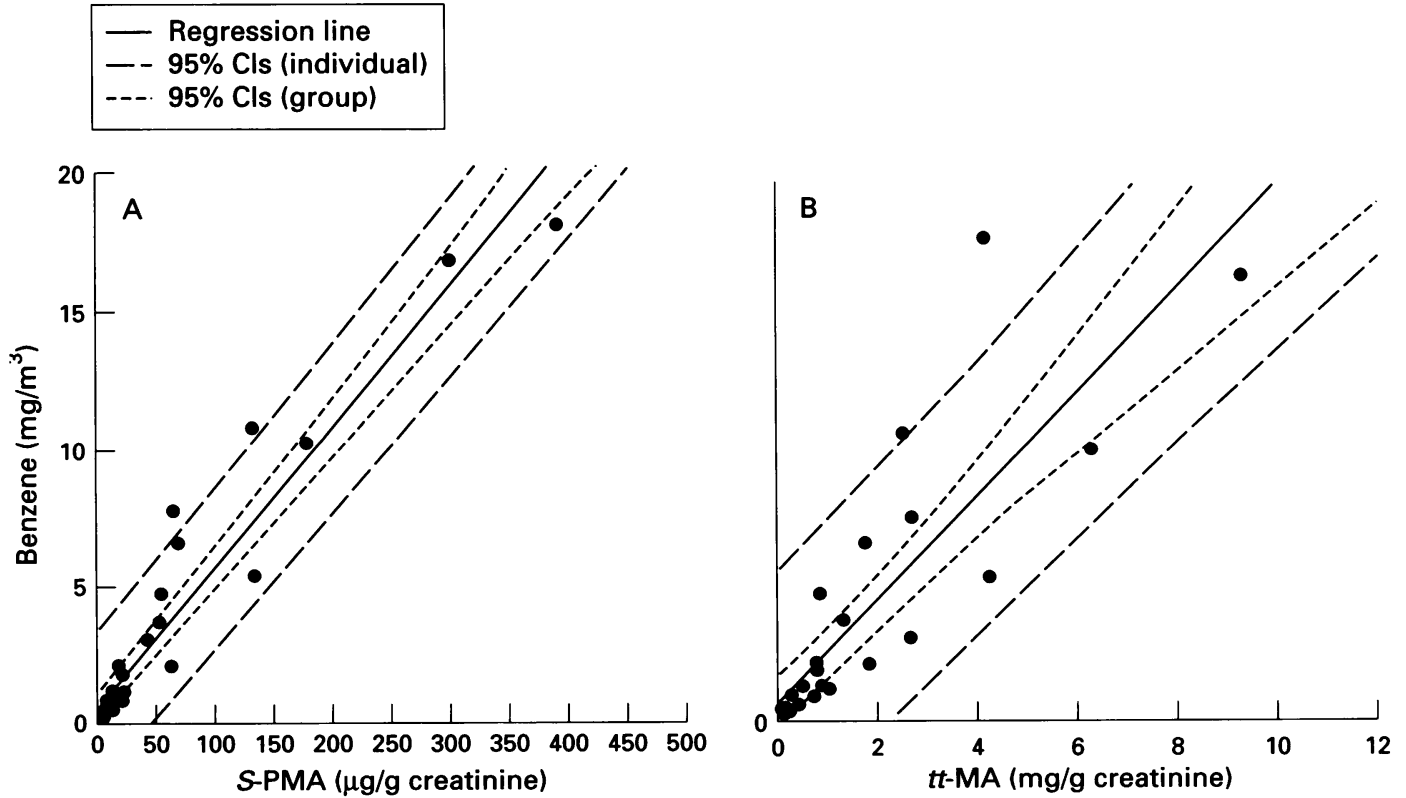
were on duty in 12 hour shifts. A separate regression analysis was made with the data collected in these studies. Again, only one set of data was included for each worker and data collected while respiratory protection was worn were excluded. Also, data collected during operations with apparent dermal exposure, as recorded by the occupational hygienist, were excluded from the analyses. Finally, the following regression equations (fig 5), with highly significant correlations $(P<0.0001)$, were obtained by analysing data sets from 28 workers:

benzene in air $\left(\mathrm{mg} / \mathrm{m},{ }^{3} 12 \mathrm{~h} \mathrm{TWA}\right)=0.0507$

$\times$ urinary $S$-PMA $(\mu \mathrm{g} / \mathrm{g}$ creatinine $)+0.518$, $r=0.959$

benzene in air $\left(\mathrm{mg} / \mathrm{m},{ }^{3} 12 \mathrm{~h}\right.$ TWA $)=1.98 \times$ urinary $t t-\mathrm{MA}(\mathrm{mg} / \mathrm{g}$ creatinine $)+0.390$, $r=0.862$

\section{Discussion}

Because of the potential adverse health effects, including acute myeloid leukaemia, that have been associated with long term occupational exposure to high concentrations of benzene (100-500 ppm), it is important to minimise exposure to benzene. To evaluate the effectiveness of control measures, biological monitoring techniques are needed that allow detection of benzene to well below $1 \mathrm{ppm}$. Due to the high and variable background of urinary phenol caused by endogenous production of phenol as well as high dietary and environmental exposure to phenol, urinary phenol is not a suitable variable for biological monitoring of exposure to benzene of below $5 \mathrm{ppm}$. In the past few years, $t t-\mathrm{MA}$ and $S$ PMA, two minor metabolites of benzene, have been proposed to replace phenol as biomarkers of exposure to benzene. These metabolites can both be measured in urine, which in our view is a prerequisite for good biological monitoring. Since its introduction in 1985, improved methods have been published for the measurement of urinary $t t-M A$ by Inoue and co-workers ${ }^{4}$ who claimed to be able to detect benzene exposure to 6-7 ppm and by Ducos and co-workers ${ }^{56}$ who improved Inoue's method by increasing the sensitivity, which allowed biological monitoring of benzene exposure down to $1 \mathrm{ppm}(8 \mathrm{~h}$ TWA). Recently, we published an improvement of the method for the determination of $S$-PMA as proposed by Stommel and coworkers $^{12}$ that allows routine biological monitoring of exposure to benzene as low as 0.3 ppm (8 h TWA). ${ }^{13}$

This paper reports the results of 12 separate investigations where measurements of both urinary $t t-M A$ and $S$-PMA were applied. The methods were compared for sensitivity, specificity, and ease of operation, to get a better insight into their suitability for routine biological monitoring of industrial exposure to low concentrations of benzene. To a limited extent urinary phenol measurements were also performed to enable a comparison of this established biological monitoring method with the more recent biological monitoring methods.

We found that measurement of $t t-\mathrm{MA}$ as described by Ducos and coworkers sometimes gave non-reproducible results. ${ }^{56}$ It turned out that this phenomenon was due to differences in the quaternary ammonium ion exchange columns. With some brands the recovery of $t t-$ MA from the columns seemed to be dependent on the $\mathrm{pH}$ of the urine sample. Alkalisation of the samples to a $\mathrm{pH}$ of 7 to 10 gave optimum recoveries that were invariably over $95 \%$. It seemed that the solid phase extraction was more efficient at a higher $\mathrm{pH}$, which resulted in cleaner extracts and a lower limit of detection $(0.01 \mathrm{mg} / \mathrm{l})$. Recently, this same favourable effect of alkalisation was also reported by Lee and coworkers who added 2 volumes of a TRIS buffer ( $\mathrm{pH} \mathrm{10)}$ to the urine samples before the solid phase extraction. ${ }^{9}$ Overall, the method proved to be simple, straightforward, and robust, which resulted in small variation coefficients within and between runs.

In the method used for the determination of $S$-PMA, the internal standard $S$-BMA was replaced by deuterated $S$-PMA in the present study for two reasons. The first reason was to improve the sensitivity and reliability of the method. In our previous report it was stated that the limit of detection varied from 1 to $5 \mu \mathrm{g} / 1$, depending mainly on matrix effects. ${ }^{13}$ It seemed that in urine specimens with a high specific gravity, S-PMA concentrations lower than about $5 \mu \mathrm{g} / 1$ could in certain cases not be attributed with certainty. With deuterated $S$ PMA as the internal standard this problem was solved and a limit of detection of $1 \mu \mathrm{g} / 1$ could be guaranteed.

The second reason was that toluene was recently reported to be metabolised in humans to $S$-BMA. ${ }^{1920}$ In many industrial processes with a risk of exposure to benzene co-exposure to toluene may occur and biotransformation of toluene to S-BMA might interfere with its use as an internal standard. In some preliminary studies we could indeed identify small amounts of $S$-BMA (up to $4 \cdot 0$ $\mu \mathrm{g} / \mathrm{l}$ ) in 10 workers exposed to low concentrations of toluene (up to $5.3 \mathrm{ppm}, 8 \mathrm{~h}$ TWA) (unpublished observations). We found in this as well as in our previous studies ${ }^{13}$ that only $0.11 \%$ of inhaled benzene is metabolised to $S$-PMA and although toluene is probably metabolised even less to $S$-BMA, there might still be serious interference in some cases as the airborne concentrations of toluene may exceed those of benzene by one or two orders of magnitude in many industrial operations. The problem of interference due to co-exposure to toluene may also be overcome with a halogenated phenylmercapturic acid, such as $S$-4-fluorophenylmercapturic acid, as the internal standard, ${ }^{12}{ }^{14}$ but this will not solve the loss of sensitivity due to matrix effects.

Because of the increased sensitivity of the measurement of $S$-PMA, the benzene uptake due to cigarette smoking was detectable in all 14 smokers from the control group (mean 
(SEM) $3.61(0.57) \mu \mathrm{g} / \mathrm{g}$ creatinine). In 20 out of the 38 non-smokers of the control group $S$-PMA could also be detected albeit in much lower concentrations $(1.99(0.32) \mu \mathrm{g} / \mathrm{g}$ creatinine). The sensitivity of the $t t-\mathrm{MA}$ measurement was too low to allow detection of $t t-\mathrm{MA}$ in most non-smokers and some smokers in the control group. The concentrations of $t t-\mathrm{MA}$ in the smokers $(0.058(0.013)$ $\mathrm{mg} / \mathrm{g}$ creatinine) and non-smokers $(0.037$ $(0 \cdot 16) \mathrm{mg} / \mathrm{g}$ creatinine) were relatively low compared with the results of a recent study on $t t$-MA conducted in Singapore where values of 0.19 and $0.14 \mathrm{mg} / \mathrm{g}$ creatinine were found in 35 smokers and 23 non-smokers, respectively. ${ }^{9}$ Although the same detection limit for $t t$-MA was reported as in our study, $t t-M A$ was detectable in all smokers and almost half of the non-smokers. The investigators thought that their relatively high background values were due to environmental pollution. In another recent study values of 0.29 and 0.09 mg $t t-\mathrm{MA} / \mathrm{g}$ creatinine were measured in 42 smokers and 42 non-smokers, respectively. ${ }^{21}$ Although the smokers in these two studies seemed to consume larger quantities of cigarettes than the moderate smokers in our control group, there was no correlation between the number of cigarettes smoked and excretion of $t t-\mathrm{MA},{ }^{9}$ but a weak correlation was found between excretion of $t t-M A$ and urinary cotinine concentrations. ${ }^{21}$

The toxicokinetics, based on spot samples, were studied for both $t t-\mathrm{MA}$ and $S$-PMA. The mean (SD) apparent urinary elimination half life $\left(t_{1 / 2}\right)$ for $S$-PMA was 9.1 (3.7) hours, which is almost identical to the $t_{1 / 2}$ of $9 \cdot 0(4 \cdot 5)$ hours previously reported. ${ }^{13}$ No discrete values for the $t_{1 / 2}$ of $t t$-MA have been reported as yet, but it has been found that in humans $t t$ MA showed a $t_{1 / 2}$ similar to that of phenol. ${ }^{5}$ Our data corroborate this finding: the estimated $t_{1 / 2}$ for $t t-M A$ was $5.0(2.3)$ hours. The average percentages of the doses of inhaled benzene that were excreted in the urine as $t t$ MA and S-PMA were $3.9 \%$ (range $1.9 \%-7 \cdot 3 \%$ ) and $0.11 \%$ (range $0.05 \%$ $0.26 \%$ ), respectively. Our value for the excretion of $t t-\mathrm{MA}$ is about twice the only value of $1.9 \%$ reported so far. ${ }^{4}$ This difference is partly explained by the lower respiration rate of 0.9 $\mathrm{m}^{3} / \mathrm{h}$ used for the estimation by Inoue and coworkers. The value found for S-PMA confirms our previous findings of a mean excretion of $0.11 \%$ as $S$-PMA with a range of 0.05 to $0.29 \% .{ }^{13}$ Most probably these rather wide ranges for both $t t-\mathrm{MA}$ and $S$-PMA are partly due to the fact that the calculations are based on spot samples, with the inherent risk of under and overestimation of areas under the curve.

Despite the fact that only spot samples were collected and that $t_{1 / 2}$ of $t t-M A$ is considerably shorter than that of S-PMA a good correlation was found between urinary concentrations of $t t$-MA and S-PMA (fig 2). Also good correlations between benzene in air and $S$-PMA as well as $t t-\mathrm{MA}$ were found (figs 4 and 5). The $95 \%$ CIs in these figures as well as the correlation coefficients for the regres- sion lines indicate that the reliability of $t t-\mathrm{MA}$ and S-PMA as biomarkers for benzene exposure during eight hour shifts are almost identical. It is obvious, however, that the reliability of $t t-\mathrm{MA}$ as a biomarker for benzene exposure during 12 hour shifts is much less than for $S$-PMA, which is totally due to its shorter elimination half life.

From these correlations it follows that exposure to $1 \mathrm{ppm}$ benzene ( $8 \mathrm{~h}$ TWA) will lead to an average excretion of $1.74 \mathrm{mg} \mathrm{t}$ $\mathrm{MA} / \mathrm{g}$ creatinine and $47 \mu \mathrm{g} S-\mathrm{PMA} / \mathrm{g}$ creatinine in urine samples collected at the end of the shift. These values seem to be confirmed by the regression equation in fig 2 , from which it can be calculated that $47 \mu \mathrm{g} S$ $\mathrm{PMA} / \mathrm{g}$ creatinine corresponds to $1.69 \mathrm{mg} t t-$ $\mathrm{MA} / \mathrm{g}$ creatinine. The value of $47 \mu \mathrm{g} / \mathrm{g}$ creatinine for $S$-PMA also agrees well with the findings from our previous studies, where a similar value was found. ${ }^{13}$ Bechtold and coworkers found in a group of 14 Chinese female workers that exposure to $4.4 \mathrm{ppm}$ benzene ( $8 \mathrm{~h}$ TWA) led to an average excretion of $6.2 \mathrm{mg} \mathrm{tt}-\mathrm{MA} / \mathrm{g}$ creatinine in urine samples collected at the end of the shift. ${ }^{7}$ This matches our results extremely well as according to the regression line obtained with our data such an exposure would lead to excretion of $6.4 \mathrm{mg} / \mathrm{g}$ creatinine. Our findings are also in good agreement with two other studies in 23 French and 38 Belgian male workers where it was found that exposure to $1 \mathrm{ppm}$ benzene (8 $\mathrm{h}$ TWA) corresponded to $1 \mathrm{mg} t t-\mathrm{MA} / \mathrm{l}^{6}$ and $1.4 \mathrm{mg} t t-\mathrm{MA} / \mathrm{g}$ creatinine, ${ }^{10}$ respectively.

In some cases skin contact with liquids containing benzene was reported by the industrial hygienist. The personal air monitoring data and the concentrations of $t t-\mathrm{MA}$ and $S$-PMA measured in the urine collected at the end of the shift strongly suggest that in these cases rather extensive dermal uptake of benzene had taken place. For example, during the replacement with bare hands of a plunger in a skimmerpump for natural gas condensate in study 1 , an airborne benzene concentration of $19.2 \mathrm{mg} / \mathrm{m}^{3}$ was measured as a $12 \mathrm{~h}$ TWA. In the urine collected at the end of the shift 12.5 mg $t t-M A$ and $798 \mu \mathrm{g} S-\mathrm{PMA} / \mathrm{g}$ creatinine were measured. According to the regression equations for the relation between airborne benzene (12 h TWA) and the urinary metabolites in urine at the end of the shift, the concentration $t t-\mathrm{MA}$ and $S$-PMA would indicate exposure to $25 \cdot 2$ and $41.0 \mathrm{mg}$ benzene $/ \mathrm{m}^{3}$, respectively. Although the value for $t t-\mathrm{MA}$ is just inside the $95 \%$ CI for individual results, it is extremely unlikely $(P<0.001)$ that the result for S-PMA is solely due to inhalation exposure.

The present study was undertaken to compare the suitabilities of $t t-M A$ and $S$-PMA for biological monitoring of low level benzene exposure. Our results confirm previous findings by ourselves and others that the measurements of both urinary $t t-\mathrm{MA}$ and $S$-PMA are sensitive tests for monitoring exposure to low concentrations of benzene. We confirmed the suitability of $S$-PMA to detect exposures to benzene as low as $0.3 \mathrm{ppm}$ ( $8 \mathrm{~h}$ TWA). This 
low level is fully due to the high specificity of the S-PMA test. The increased sensitivity achieved by lowering the detection limit led to possible detection of exposure to benzene caused by moderate smoking. Despite the fact that we were able to improve the method of measurement of urinary $t t-\mathrm{MA}$ by a more efficient clean up, we also confirmed the conclusions by others that with $t t-M A$, at best, exposures of over $0.5 \mathrm{ppm}$ can reliably be detected. ${ }^{1014}$ The reason for this is that in unexposed people relatively high background concentrations of $t t-\mathrm{MA}$ are consistently found..$^{8101121}$ This background may possibly be due to consumption of sorbic acid, which is used as a preservative in many foodstuffs. ${ }^{5}$ There may be a preference for $t t-M A$ over $S$-PMA as a biomarker for benzene exposures of more than $1 \mathrm{ppm}$ ( $8 \mathrm{~h}$ TWA) as HPLC is easier to operate than gas chromatographymass spectroscopy and in most cases is also more readily available. Due to the rather expensive solid phase extraction, the cost/ sample of analysis of $t t-M A$ is about equal to that of $S$-PMA. A disadvantage of $t t-M A$ for biological monitoring of exposure to benzene is that its formation is decreased in the event of co-exposure to other aromatic hydrocarbons, ${ }^{22}$ which may lead to underestimation of benzene exposure. Although we have not yet been able to confirm it, our findings in study 12 , where hardly any $S$-PMA was found in a man treated with high doses of an inducer of the hepatic mixed function oxidase, might indicate that the formation of S-PMA may be influenced by co-exposure as well.

The technical assistance by $\mathrm{H}$ van der Waal, $\mathrm{J}$ Kweekel, and Y N Vreugd (Shell Biomedical Laboratory; Shell Nederland Raffinaderij/Chemie B V, Rotterdam, The Netherlands) is gratefully acknowledged.

1 Yardley-Jones A, Anderson D, Parke DV. The toxicity of benzene and its metabolism and molecular pathology in human risk assessment. Br f Ind Med 1991;48:437-44.

2 Angerer J, Scherer G, Schaller KH, Müller J. The determination of benzene in human blood as an indicator of environmental exposure to volatile aromatic compounds. Fresenius fournal of Analytical Chemistry 1991; 339:740-2.

3 Brugnone F, Perbellini L, Maranelli G, Romeo L, Guglielmi G, Lombardini F. Reference values for blood benzene in the occupationally unexposed general popu- lation. Int Arch Occup Environ Health 1992;64:179-84

4 Inoue O, Seiji K, Nakatsuka H, Watanabe T, Yin SN, Li $\mathrm{GL}$, et al. Urinary $t, t$-muconic acid as an indicator of exposure to benzene. Br $\mathcal{F}$ Ind Med 1989;46:122-7.

5 Ducos P, Gaudin R, Robert A, Francin JM, Maire C. Improvement in HPLC analysis of urinary trans, transmuconic acid, a promising substitute for phenol in the assessment of benzene exposure. Int Arch Occup Environ Health 1990;62:529-34.

6 Ducos P, Gaudin R, Bel J, Maire C, Francin JM, Robert $\mathrm{A}$, et al. trans,trans-Muconic acid, a reliable biological indicator for the detection of individual benzene exposure down to the ppm level. Int Arch Occup Environ sure down to the ppm
Health 1992;64:309-13.

7 Bechtold WE, Lucier G, Birnbaum LS, Yin SN, Li GL, Henderson RF. Muconic acid determinations in urine as a biological exposure index for workers occupationally exposed to benzene. Am Ind Hyg Assoc F 1991;52:473-8.

8 Johnson ES, Lucier G. Perspectives on risk assessment impact of recent reports on benzene. Am $₹$ Ind Med 1992;21:749-57.

9 Lee BL, New AL, Kok PW, Ong HY, Shi CY, Ong CN. Urinary trans,trans-muconic acid determined by liquid chromatography: application in biological monitoring of benzene exposure. Clin Chem 1993;39:1788-92.

10 Lauwerys RR, Buchet JP, Andrien F. Muconic acid in urine: a reliable indicator of occupational exposure to urine: a reliable indicator of occupational

11 Rauscher D, Lehnert G, Angerer J. Biomonitoring of occupational and environmental exposures to benzene by measuring trans,trans-muconic acid in urine. Clin by measuring trans, trant

12 Stommel P, Müller G, Stücker W, Verkoyen C, Schöbel S, Norpoth $K$. Determination of S-phenylmercapturic acid in the urine-an improvement on the biological monitoring of benzene exposure. Carcinogenesis 1989;10 279-82.

13 Van Sittert NJ, Boogaard PJ, Beulink GDJ. Application of the urinary $S$-phenylmercapturic acid test as a biomarker for low levels of exposure to benzene in industry. $\mathrm{Br} \mathcal{J}$ for low levels of exposure

14 Popp W, Rauscher D, Müller G, Angerer J, Norpoth K. Concentrations of benzene in blood and $S$-phenylmercapturic acid and $t, t$-muconic acid in urine in car mechanics. Int Arch Occup Environ Health 1994;66:1-6.

15 CONCAWE's petroleum products and health management groups. Gasolines. Product dossier 92/103. Brussels: CONCAWE, 1992.

16 Rumpf $P$. Darstellung, Charakteriserung und Trennung der Merkaptursäuren von Benzol, Toluol, Ethylbenzol und Xylolen durch GC-MS Analyse. Hamburg: Universität Hamburg, 1981. (PhD Thesis.)

17 NIOSH. Back up data report benzene, method S311. Manual of analytical methods, 2nd ed. Vol 3. Cincinnati: DHEW (NIOSH), 1977. (Publication No 77-157C.)

18 Doctor JH, Zielhuis R. Phenol excretion as a measure of occupational exposure. Ann Occup Hyg 1967;10:317-36.

19 Takahashi S, Matsubara K, Hasegawa M, Akane A Shiono $H$. Detection and measurement of $S$-benzyl- $N$ Shiono $\mathrm{H}$. Detection and measurement of $S$-benzyl- $N$ acetylcysteine in urine of toluene sniffers using cap

20 Takahashi S, Kagawa M, Shiwaku K, Matsubara K Determination of $S$-benzyl- $N$-acetyl-L-cysteine by gas chromatography/mass spectrometry as a new marker of toluene exposure. $\mathcal{F}$ Anal Toxicol 1994;18:78-80.

21 Melikian AA, Prahalad AK, Hoffmann D. Urinary trans, trans-muconic acid as an indicator of exposure to benzene in cigarette smokers. Cancer Epidemio Biomarkers Prev 1993;2:47-51.

22 Inoue $O$, Seiji $K$, Watanabe $T$, Kasahara $M$, Nakatsuka $H$ Yin S, et al. Mutual metabolic suppression between benzene and toluene in man. Int Arch Occup Environ Health zene and toluene in 